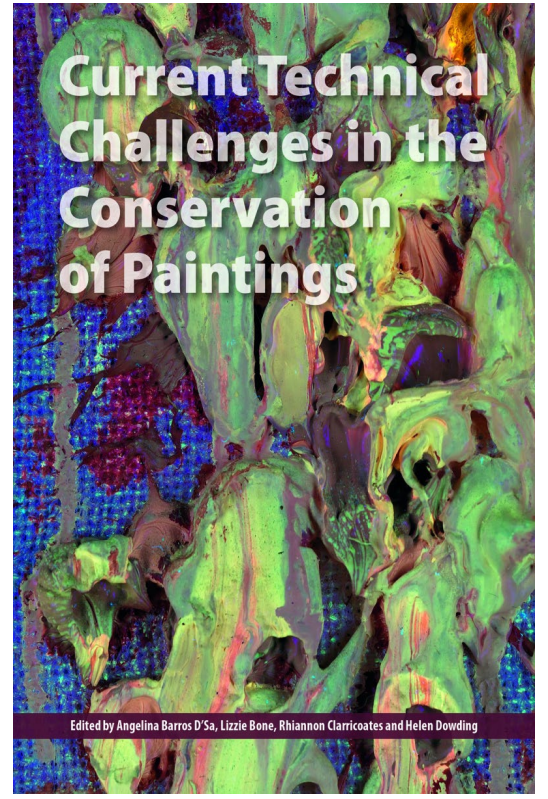

\section{Current Technical Challenges in the Conservation of Paintings}

\author{
Angelina Barros D'Sa, Lizzie Bone, Rhiannon \\ Clarricoates, Helen Dowding (eds)
}

\author{
Editorial. Archetype \\ Páginas: 126 \\ Ilustraciones: 59 \\ Dimensions: 246 × $175 \mathrm{~mm}$
}

ISBN: 9781909492318
Esta breve monografía de la editorial británica Archetype recoge los trabajos presentados en el congreso Modern Conservation: What's new? celebrado en la Wallace Collection (Londres) en Octubre de 2014, organizada por el Grupo de Pintura ICON perteneciente al International Institute for Conservation of Historic and Artistic Works (IIC). En ella se reúnen una serie de trabajos con innovadores enfoques sobre técnicas, metodologías y materiales empleados en tratamientos de conservación-restauración, con especial atención a los desafíos planteados por las obras pictóricas contemporáneas.

Es de destacar la voluntad de celeridad en su publicación que, según los editores, ha estado motivada por la necesidad de la inmediatez y renovación constante en el contexto de la conservación-restauración, lo que sería deseable en otras muchas publicaciones de nuestro ámbito. También es conveniente señalar que se trata de una referencia bibliográfica con un amplio enfoque, hecho que se evidencia en la heterogénea procedencia de los autores, entre los que se incluyen restauradores de la Tate Gallery, National Portrait Gallery, Getty Conservation Institute, así como conservadores-restauradores de museos daneses, noruegos, holandeses, polacos y coreanos, técnicos de la industria y restauradores de la empresa privada.

La monografía enfrenta al lector al desafío de los nuevos materiales y técnicas y a los problemas de alta complejidad técnica que presentan este tipo de pinturas, todo ello con un enfoque eminentemente práctico. De este modo, se incluyen trabajos sobre nuevas metodologías de limpiezas para pinturas contemporáneas no barnizadas, diferentes tratamientos de pinturas recientes que presentan fenómenos de exudaciones (problema cada vez más extendido en el ámbito de la conservación-restauración y que comporta una importante dificultad de tratamiento), casos de estudio en los que se evalúa la eficacia de consolidantes comercializados actualmente, la evaluación de barnices actuales como alternativa al empleo de barnices tradicionales, el uso de la cinta kinesiológica como adhesivo temporal en tratamientos de rasgados o el empleo de paneles para la reducción de vibraciones en pinturas con soporte flexible, entre otros.

De entre todos ellos, resulta de especial interés la puesta al día que Ormsby, Keefe, Phenix y Learner realizan sobre el empleo de sistemas de la limpieza de superficies pictóricas contemporáneas no barnizadas, en el que se trata el empleo de los tensoactivos ECOSURF ${ }^{\mathrm{TM}} \mathrm{EH}$ y de las microemulsiones. Por otro lado, la publicación incluye dos trabajos en los que se plantea la problemática de tratamiento de las exudaciones y la licuefacción de pinturas contemporáneas, problema tan escasamente tratado como frecuente.

Otro de los trabajos presentados, firmado por Andrea Krez, plantea el innovador uso de la cinta adhesiva kinesiológica en diversos tratamientos del soporte de lienzo, estudiando su composición, propiedades y peculiaridades de su uso. Esta cinta constituye una interesante alternativa al uso de las cintas adhesivas disponibles hasta la fecha $y$, tal y como muestra el 
trabajo, puede ser empleada con éxito en diferentes tratamientos de conservación-restauración.

Finalmente, resulta especialmente ilustrativo el artículo referente a la colocación de paneles en contacto directo o flotantes en el reverso del bastidor con el fin de reducir las vibraciones de las pinturas sobre lienzo; esta práctica, cada vez más extendida, surge como alternativa al reentelado o la colocación de traseras. En este trabajo su autora, Laura Hinde, repasa las diferentes tipologías de paneles empleados en el Smithsonian American Art Museum (Washington), la National Portrait Gallery (Londres) o el Museum of Fine Arts (Houston). Del mismo modo, la autora revisa y estudia detalladamente los diferentes tipos de adhesivos y paneles comerciales empleados para este fin.

Silvia García Fernández-Villa

Facultad de Bellas Artes. UCM 